\title{
Developmental changes in ERP correlates of spoken word recognition during early school years: A phonological priming study.
}

Citation for published version (APA):

Bonte, M. L., \& Blomert, L. P. M. (2004). Developmental changes in ERP correlates of spoken word recognition during early school years: A phonological priming study. Clinical Neurophysiology, 115, 409423. https://doi.org/10.1016/S1388-2457(03)00361-4

Document status and date:

Published: 01/01/2004

DOI:

10.1016/S1388-2457(03)00361-4

Document Version:

Publisher's PDF, also known as Version of record

Document license:

Taverne

Please check the document version of this publication:

- A submitted manuscript is the version of the article upon submission and before peer-review. There can be important differences between the submitted version and the official published version of record.

People interested in the research are advised to contact the author for the final version of the publication, or visit the DOI to the publisher's website.

- The final author version and the galley proof are versions of the publication after peer review.

- The final published version features the final layout of the paper including the volume, issue and page numbers.

Link to publication

\footnotetext{
General rights rights.

- You may freely distribute the URL identifying the publication in the public portal. please follow below link for the End User Agreement:

www.umlib.nl/taverne-license

Take down policy

If you believe that this document breaches copyright please contact us at:

repository@maastrichtuniversity.nl

providing details and we will investigate your claim.
}

Copyright and moral rights for the publications made accessible in the public portal are retained by the authors and/or other copyright owners and it is a condition of accessing publications that users recognise and abide by the legal requirements associated with these

- Users may download and print one copy of any publication from the public portal for the purpose of private study or research.

- You may not further distribute the material or use it for any profit-making activity or commercial gain

If the publication is distributed under the terms of Article $25 \mathrm{fa}$ of the Dutch Copyright Act, indicated by the "Taverne" license above, 


\title{
Developmental changes in ERP correlates of spoken word recognition during early school years: a phonological priming study
}

\author{
Milene Bonte*, Leo Blomert \\ Department of Cognitive Neuroscience, Faculty of Psychology, Universiteit Maastricht, P.O. Box 616, 6200 MD Maastricht, The Netherlands
}

Accepted 3 October 2003

\begin{abstract}
Objective: We investigated event-related potential (ERP) correlates of developmental changes in spoken word recognition during early school years. We focused on implicit processing of word onsets as this may change considerably due to vocabulary growth and reading acquisition.

Methods: Subjects were pre-schoolers (5-6 years), beginning readers (7-8 years) and adults. Two experiments examined phonological onset priming effects on ERP measures in an auditory lexical decision task. Primes were words (Expt. 1) or non-words (Expt. 2).

Results: ERPs elicited by words showed clear developmental changes in ERP latency and morphology, especially with regard to early negativities like the N1. Prominent priming effects were an enhanced N400 amplitude due to alliterating word primes in beginning readers, and typical phonological N400 reductions due to alliterating non-word primes in all groups. Priming further led to opposite early effects with word primes $\left(\mathrm{N} 1 / \mathrm{N}_{200}\right.$ reduction) vs. non-word primes (P1/N1 enhancement) in all groups.

Conclusions: These changes in ERP morphology and priming effects suggest that the lexical system undergoes substantial restructuring at the level of phonological processing and representation. In particular, our results indicate distinct processing of word onsets in beginning readers, confirming that vocabulary growth and the acquisition of reading may critically contribute to the formation of a fully segmental lexical system.
\end{abstract}

(C) 2003 International Federation of Clinical Neurophysiology. Published by Elsevier Ireland Ltd. All rights reserved.

Keywords: Auditory ERP; Children; Adults; Word recognition; Phonological priming

\section{Introduction}

The recognition of spoken words requires mapping of a continuous stream of speech sounds onto meaning-based neural representations. As the auditory speech signal does not consist of discrete units like words, syllables or phonemes, specialized neural operations are needed to derive meaning from this acoustic information.

The neural system subserving these operations develops during early childhood. The acquisition of phonetic contrasts and structural regularities of the native language occurring during infancy forms the basis for word segmentation in fluent speech and has been studied quite extensively (for a review see Jusczyk, 1999). In contrast, less is known about developmental changes in the access and representation of lexical information, i.e. in

\footnotetext{
* Corresponding author. Tel.: + 31-43-388-4036; fax: + 31-43-388-4125.

E-mail address: m.bonte@psychology.unimaas.nl (M. Bonte).
}

the transformation of words into meaning. In adults, these aspects of lexical processing may rely on the analysis of subtle phonetic details and capitalize on word-initial information (Marslen-Wilson and Warren, 1994; McQueen and Cutler, 2001). In children, words may be recognized in a more holistic manner, both with respect to the detail of phonetic/phonological representations and to the importance of position-specific information (Jusczyk, 1993; Metsala and Walley, 1998). Initially, the acquisition of novel words may be aided by the exploitation of salient features throughout words (e.g. Walley, 1988). Then, during vocabulary growth, the implementation of more finegrained, segmental representations is necessary to enable the distinction of an increasing number of words with overlapping acoustic properties (Jusczyk, 1993; Metsala and Walley, 1998). Such a restructuring of lexical representation may be organized around salient and robust word initial information, and eventually leads to the fast and efficient adult word recognition system (Jusczyk, 1993). This process 
may have a protracted developmental course and probably extends over early school years. In particular, the formation of fully specified phonological representations may critically depend on the acquisition of reading (Liberman, 1973; Morais et al., 1986).

Here we investigate the neural correlates of these developmental changes in lexical restructuring. We measured event-related potentials (ERPs) during an auditory lexical decision task in combination with phonological onset priming in pre-schoolers (5-6 years), beginning readers ( $7-8$ years) and adults. Primes were words (Expt. 1) and non-words (Expt. 2). This enabled us to compare ERP correlates of onset priming due to word processing, which requires both pre-lexical and lexical processing, and nonword processing, which mainly requires pre-lexical processing. The influence of phonological priming on word onsets was expected to change dependent on the subject's level of lexical restructuring. Our groups were thus selected to represent 3 different levels of lexical organization, ranging from a relatively unsegmented, holistic lexical organization (pre-schoolers) to an automatized and completely segmented lexical system (adults), with the beginning readers representing an intermediate level of lexical organization, with ongoing major developments in segmental restructuring (e.g. Goswami et al., 2003).

Dependent on the level at which the primes exert their influence, we may expect effects of phonological priming on different ERP components which have been related to phonetic/phonological processing in adults. One of these ERP effects is a modulation of a late negative potential (e.g. Praamstra et al., 1994; Rugg, 1984), comparable to the semantic N400 effect originally reported by Kutas and Hillyard (1980). The semantic N400 is elicited by visual and auditory words presented in sentences, lists or pairs. Its amplitude appears to reflect the extent to which a word is semantically primed, i.e. a word which is semantically expected elicits a reduced N400 (for a review see Kutas and Van Petten, 1994). Similarly, phonological priming, i.e. alliteration or rhyme, has been found to reduce the amplitude of the N400 waveform (e.g. Grossi et al., 2001; Praamstra et al., 1994; Radeau et al., 1998), sometimes called N450 (Rugg, 1984). These phonological N400 effects occur earlier for word onset (alliteration) than rhyme priming, which suggests that they may be a useful index of the temporal dynamics of spoken word processing (Praamstra et al., 1994). Both semantic and phonological N400 effects depend on the level of attention directed to the stimuli and might belong to a broader category of 'discordance negativities' (Perrin and Garcia-Larrea, 2003). However, phonological N400 effects are less robust than their semantic counterpart and are mainly reported in experiments using active phonological tasks (Perrin and Garcia-Larrea, 2003).

In studies using a variation of the semantic N400paradigm in which not only semantic, but also phonological expectancy is systematically varied, unexpected word onsets have been shown to modulate a separate negativity at a latency of 200-300 ms, preceding the N400 (e.g. Connolly and Phillips, 1994; Hagoort and Brown, 2000; Van den Brink et al., 2001). Connolly and Phillips (1994), for example, reported a negative potential (phonological mismatch negativity, PMN) around $270 \mathrm{~ms}$, elicited whenever sentence final words had a phonologically unexpected onset (e.g. 'Don caught the ball with his glove'), with a double effect, i.e. PMN and a semantic $\mathrm{N} 400$, in case of a double violation, i.e. phonological and semantic (e.g. 'The dog chased the cat up the queen'). Negativities like PMN have been interpreted to reflect the phonological processing of word onsets and/or the initial activation of lexical candidates. Other studies using the same paradigm, failed to find a separate negativity preceding the N400, but found a relation between processing of word onsets and onset latency of the semantic N400 effect (e.g. Helenius et al., 2002; Van Petten et al., 1999).

Psycholinguistic experiments in adults suggest that word-initial speech input may activate multiple word candidates already on the basis of the first 100-150 ms of a word, or 1-2 phonetic segments (Marslen-Wilson, 1987). Furthermore, ERP and magneto-encephalographic (MEG) studies deploying the mismatch negativity (MMN) as a measure of the automatic comparison of phonemic contrasts, suggest that at 150-200 ms after speech onset, native vs. nonnative phonetic contrasts are already processed differently (Näätänen et al., 1997; Winkler et al., 1999) and phonological categories may have been accessed (Phillips et al., 2000; Vihla et al., 2000). The neural sources underlying the MMN effect may partly overlap with those of the auditory N1 (Näätänen and Picton, 1987). Whereas the MMN is assumed to reflect an automatic change detection response elicited by any discriminable change in a repeated sound, the auditory N1 reflects an ubiquitous response to any sound onset in healthy adults (Näätänen and Picton, 1987). The N1 has been associated with processing in non-primary auditory cortex and may selectively respond to the phonetic structure of speech sounds (Ackermann et al., 1999; Eggermont and Ponton, 2002; Eulitz et al., 1995; Kuriki and Murase, 1989; Tiitinen et al., 1999). Furthermore, recent studies suggested that neural processes underlying the $\mathrm{N} 1$ may contribute significantly to the processing of word onsets during the perception of continuous speech (Sanders and Neville, 2003a,b; Sanders et al., 2002). Thus, in our experiments, the N1 may be a good candidate to look for effects of early acoustic/phonetic processing of word onsets during the recognition of spoken words.

During development, the time window(s) influenced by task manipulations involving word onset processing may also change. Little is known about the ERP elicited by spoken words in young children and about its comparability to the adult ERP. Thus, ERP studies on spoken word recognition in children are essential to understand the morphology of the ERP signal and how it may reflect 
the development of underlying lexical organization and retrieval (Jusczyk, 1993; Metsala and Walley, 1998). To our knowledge there are no previous reports of such developmental ERP data. However, ERP/MEG studies on processing of clicks, tones and consonant-vowel stimuli provide important information regarding developmental changes in general, and with respect to speech specific auditory processing. These studies revealed that the morphology of ERPs and corresponding magnetic fields changes substantially until the late teens (e.g. Bruneau et al., 1997; Ceponiene et al., 1998, 2002; Csepe, 1995; Kraus et al., 1993; Paetau et al., 1995; Pang and Taylor, 2000; Ponton et al., 2000; Shafer et al., 2000; Sharma et al., 1997; Takeshita et al., 2002). Whereas the auditory ERP in adults is consistently characterized by a P1-N1-P2 complex, results are less clear in children. The auditory ERP which is most robustly observed in children is a biphasic positivenegative complex (e.g. Ceponiene et al., 2002; Takeshita et al., 2002). The early positivity typically occurs with a latency of about $100 \mathrm{~ms}$ and has been consistently related to the adult P1 (e.g. Sharma et al., 1997). The subsequent negativity has a more variable latency which centers around 200-250 ms, and has often been called N2 or N250 (Ceponiene et al., 2002; Takeshita et al., 2002). Several reports have suggested that this $\mathrm{N} 2$ observed in children does not correspond to the component referred to as the N1 in adults (Csepe, 1995; Shafer et al., 2000; Takeshita et al., 2002). The childhood N2 possibly relates to the adult N2 and its prominent amplitude in childhood may reflect auditory sensory processing until the efficient adult cortical networks are established (Takeshita et al., 2002). Overall, the component structure of the auditory ERP in children, and especially the presence of an N1, may depend on stimulus content, e.g. tone frequency (Csepe, 1995) and inter stimulus intervals (ISIs) (Bruneau et al., 1997; Ceponiene et al., 1998, 2002; Paetau et al., 1995). Determination of the maturational course of the N1 and its recording possibilities, are further complicated by the fact that this component consists of several subcomponents, each with its own dependence on stimulus parameters, state of the subject and developmental course (see Bruneau and Gomot, 1998; Bruneau et al., 1997; Pang and Taylor, 2000; Ponton et al., 2000). Whereas these studies provide useful information on the complex pattern of developmental changes in ERPs in response to meaningless auditory (speech) stimuli, it is less clear what changes to expect in ERPs elicited to words during an auditory lexical decision task as used in the present study.

In summary, based on the review of ERP studies in adults, we expect that several components may be influenced by phonological onset priming. First, priming effects related to acoustic/phonetic processing of word onsets may modulate the N1. Second, priming effects on subsequent phonological processing, may modulate a PMNlike negativity. And third, in case priming has an effect on a phonological/lexical level, we expect priming effects in the N400 window. Based on cognitive models of lexical development (Jusczyk, 1993; Metsala and Walley, 1998) and previous developmental ERP studies, we expect changes in the level of segmental restructuring to be reflected in the size and nature of phonological priming effects. Furthermore, we expect additional group differences, independent of priming, in ERP latency and morphology, especially with regard to the early negativities.

\section{Methods}

\subsection{Subjects}

Thirty-five subjects (16 pre-schoolers, 10 beginning readers and 9 adults) participated in Expt. 1 and 26 subjects (9 pre-schoolers, 10 beginning readers and 7 adults) in Expt. 2. In Expt. 1, data of 27 subjects were included in the analysis, including 11 pre-schoolers ( 5 female; mean age: $6.2 \pm 0.41$ years), 8 beginning readers ( 6 female; mean age: $7.9 \pm 0.41)$ and 8 adults ( 6 female; mean age: $24.5 \pm 3.3$ ). In Expt. 2, data of 23 subjects were included in the analysis, including 8 pre-schoolers ( 4 female; mean age: $6.1 \pm 0.43$ ), 8 beginning readers ( 6 female; mean age: $7.9 \pm 0.38)$ and 7 adults ( 5 female; mean age: $24.7 \pm 3.5$ ). In total, data of 6 pre-schoolers, 4 beginning readers, and 1 adult were discarded, due to excessive movement artifacts, and/or an incidental technical problem. Of each age group, 7 subjects participated in both experiments.

Adults were paid for participation and children were given a present. Informed consent was obtained from all the adult subjects and parents of children, according to the approval by the Ethical Committee of the Faculty of Psychology at the University of Maastricht. All subjects were right-handed native Dutch speakers with normal hearing. Handedness was assessed with Annett's Handedness Questionnaire (Annett, 1979). All adult subjects and parents of children reported the absence of any history of hearing loss. Children were given standardized language tests (see Table 1); including a passive vocabulary test (Bleichrodt et al., 1984), a word completion test (Van Bon, 1982), a phoneme deletion test ${ }^{1}$ (unpublished test, Regional Institute of Dyslexia, Maastricht), and two reading tests, word reading (Brus and Voeten, 1999) and non-word reading (Van den Bos et al., 1999). Pre-schoolers were only selected for participation in case they were not yet able to read or write. All pre-schoolers scored within normal limits on the vocabulary and word completion tests, but scored

\footnotetext{
${ }^{1}$ Children heard simple one-syllable words via headphones and were asked to repeat these words with the omission of one phoneme, of which the sound was given. Phonemes to be deleted occurred at variable word positions and deletion always resulted in another existing word. All but 3 items required the deletion of a consonant in a consonant cluster (e.g. Brood (bread)). The items which preschoolers performed correctly were most of the time among the 3 items in which the critical consonant was followed by a vowel (i.e. Meisje (girl)).
} 
Table 1

Mean (SD) performance on language tests for pre-schoolers and beginning readers

\begin{tabular}{|c|c|c|}
\hline & $\begin{array}{l}\text { Pre-schoolers } \\
(n=12)\end{array}$ & $\begin{array}{l}\text { Beginning } \\
\text { readers }(n=9)\end{array}$ \\
\hline Age (years) & $6.2(0.4)$ & $7.9(0.4)$ \\
\hline $\begin{array}{l}\text { Passive vocabulary (C-scores, } \\
\text { norm beginning readers) }\end{array}$ & $3.4(1.4)$ & $6.3(1.8)$ \\
\hline $\begin{array}{l}\text { Passive vocabulary (C-scores, } \\
\text { norm pre-schoolers) }\end{array}$ & $7.5(1.6)$ & - \\
\hline $\begin{array}{l}\text { Word completion (C-scores } \\
\text { max. norm } 7 \text { yrs) }\end{array}$ & $5.6(1.3)$ & $4.6(1.2)$ \\
\hline $\begin{array}{l}\text { Phoneme deletion } \\
\text { (\% correct, total } 28 \text { items) }\end{array}$ & $9.5 \%(16 \%)$ & $95 \%(4 \%)$ \\
\hline Word reading (C-scores) & No reading & $6.1(1.1)$ \\
\hline Non-word reading (C-scores) & No reading & $6.3(1.2)$ \\
\hline
\end{tabular}

very low or were not able at all to perform the phoneme deletion test. The latter result agrees with the finding that in all languages studied so far, children typically perform close to floor in tasks measuring phoneme awareness prior to learning to read (Liberman, 1973; Morais et al., 1986). All beginning readers included in the analysis scored within the normal range on the performed language tests.

\subsection{Materials}

Stimuli were mono-morphemic bisyllabic Dutch words and non-words, all with a consonant onset. Non-words were created from words by changing one or two phonemes according to Dutch phonotactic rules. Words were selected using estimates of age of acquisition (AOA) rather than adult frequency ratings. The choice of this selection criterion was indicated by a recent study in which AOA was shown to be a more sensitive measure of lexical familiarity - than either word frequency or neighborhood density - for making developmental comparisons of spoken word recognition in children (Garlock et al., 2001). Our AOA criterion was 6 years or earlier. Estimates of AOA were based on two published ratings: (1) vocabulary estimates of 6-year-olds (Schaerlaekens et al., 1999), (2) AOA of Dutch words (Ghyselinck et al., 2000), and a subsequent student/parent familiarity rating of the selected words.

The stimuli were spoken by a female native Dutch speaker and recorded on a DAT recorder at a sampling rate of $44.01 \mathrm{kHz}$. Word onsets and offsets were determined using a speech waveform editor. The digitized stimuli were D/A converted with an 8 bit resolution, bandpass filtered ( $30 \mathrm{~Hz}$ to $10.6 \mathrm{kHz}$ ) and re-sampled at $22.05 \mathrm{kHz}$. The mean acoustical duration of word primes was $596 \mathrm{~ms}$ (range: 413-819), non-word primes $619 \mathrm{~ms}$ (range: 409-796), alliterating word targets $576 \mathrm{~ms}$ (range: 387-789), unrelated word targets $603 \mathrm{~ms}$ (range: 464-760) alliterating non-word targets $626 \mathrm{~ms}$ (range: 433-864), and unrelated

\begin{tabular}{|c|c|c|}
\hline \multirow[t]{2}{*}{ Primes } & \multicolumn{2}{|l|}{ Targets } \\
\hline & Unrelated & Alliterating \\
\hline \multicolumn{3}{|l|}{ (a) Experiment 1} \\
\hline $\begin{array}{l}\text { word } \\
\text { morgen (morning) }\end{array}$ & $\begin{array}{l}\text { word } \\
\text { zuster (sister) }\end{array}$ & $\begin{array}{l}\text { word } \\
\underline{\text { modder }(\mathrm{mud})}\end{array}$ \\
\hline $\begin{array}{l}\text { word } \\
\text { hamer (hammer) }\end{array}$ & $\begin{array}{l}\text { non-word } \\
\text { zeppel }\end{array}$ & $\begin{array}{l}\text { non-word } \\
\text { hapel }\end{array}$ \\
\hline \multicolumn{3}{|l|}{ (b) Experiment 2} \\
\hline $\begin{array}{l}\text { nonword } \\
\text { morben }\end{array}$ & $\begin{array}{l}\text { word } \\
\text { zuster (sister) }\end{array}$ & $\begin{array}{l}\text { word } \\
\text { modder (mud) }\end{array}$ \\
\hline $\begin{array}{l}\text { non-word } \\
\text { hazer }\end{array}$ & $\begin{array}{l}\text { non-word } \\
\text { zeppel }\end{array}$ & $\begin{array}{l}\text { non- word } \\
\text { hapel }\end{array}$ \\
\hline \multicolumn{3}{|c|}{ ERP epoch } \\
\hline Prime & Target & \\
\hline
\end{tabular}

Fig. 1. Design and example stimuli of Expt. 1 (a) and Expt. 2 (b). Primetarget pairs were either phonologically unrelated (unrelated) or shared the initial two phonemes (alliterating).

non-word targets 592 ms (range: 353-786). Statistical comparison of prime or target lengths only showed significant differences between unrelated and related nonword targets $(P<0.025)$.

\subsection{Design}

In both experiments, we used an auditory lexical decision task in combination with phonological onset priming. In Expt. 1 primes were words, in Expt. 2 primes were nonwords. Prime-target pairs were either phonologically unrelated (unrelated), or shared the initial two phonemes (alliterating) (see Fig. 1a,b). In both experiments, the same set of targets was used: 116 words and 116 non-words. Within each experiment, primes were presented twice, in separate blocks, once in combination with an unrelated and once with an alliterating word or non-word target. In this way targets were never repeated within the same experiment. Prime and target were never semantically related and had the same syllable stress pattern.

\subsection{Procedure}

Subjects were tested individually in a sound-attenuating and electrically shielded room. They were seated in a comfortable chair in front of a computer monitor. Before the experiment started, subjects performed a separate $5 \mathrm{~min}$ block of practice trials with stimuli that did not occur in the experiment. Stimuli were presented binaurally through loudspeakers at $65 \mathrm{~dB}$ SPL. Each trial started with a fixation cross which stayed on the screen until the end of the trial. Subjects were instructed not to move their eyes and sit quietly especially when the fixation cross was present. At a variable interval (400-1000 ms) after appearance of the fixation cross the prime was presented. Prime-target stimulus onset asynchrony (SOA) was $1 \mathrm{~s}$. Maximum response time was set at $3000 \mathrm{~ms}$, the intertrial interval was 
$2000 \mathrm{~ms}$. Subjects were told to ignore the primes, attend carefully to the targets and press the right button in case of real words and the left button in case of non-words. Both speed and accuracy were encouraged. Cartoons of a blue thumb up (near right button) and a red thumb down (near left button) were used to prevent confusion of response hands. Children were given a short break every 20 trials. Both experiments consisted of 12 blocks, after the first 6 blocks there was a longer break. Between subjects, we varied the order in which Expts. 1 and 2 were performed. Within subjects, there was a break of at least 2 weeks (and maximally 3 months) between the two experiments.

\subsection{EEG recording and data analysis}

EEG data were recorded from 29 electrodes (International 10-20 system): FP1/2, F7/8, F3/4, Fz, FT8/7, FC3/4, FCz, T3/4, C3/4, Cz, TP7/8, CP3/4, T5/6, P3/4, Pz, $\mathrm{O} 1 / 2$, Oz. Blinks and vertical eye movements were monitored with electrodes placed at the sub- and supraorbital ridge of the left eye. Lateral eye movements were monitored by a bipolar montage using two electrodes placed on the right and left external canthus. All electrode impedance levels (EEG and EOG) were kept below $5 \mathrm{k} \Omega$. Electrophysiological signals were amplified with a bandpass filter of $0.01-50 \mathrm{~Hz}$ and digitized at a rate of $250 \mathrm{~Hz}$. EEG signals were recorded with a left mastoid reference, and were offline re-referenced to the average of the right and left mastoid. Epochs of $1200 \mathrm{~ms},-200$ to $1000 \mathrm{~ms}$ relative to target onset, were created from the continuous EEG data. Only trials with correct responses were analyzed. Data were baseline corrected to a $100 \mathrm{~ms}$ pre-stimulus interval, 1-30 $\mathrm{Hz}$ bandpass filtered, and trials containing conspicuous artifacts were rejected (the averages of all subjects, with the exception of one pre-reader, met our rejection criterion of $30 \%$, corresponding to the inclusion of at least 40 trials per condition). In Expt. 1, the mean number of the accepted epochs in the grand averages for alliterating and unrelated word and non-word targets were 45, 44, 47 and 48 in pre-schoolers, 52, 51, 51 and 52 in normal readers and 55, 56, 56 and 57 in adults. In Expt. 2, the mean number of the accepted epochs were 48, 47, 50, and 49 in pre-schoolers, 52, 51, 52 and 51 in normal readers and 56, 56, 57 and 57 in adults. Vertical eye-movements (i.e. blink artifacts) were corrected (Semlitsch et al., 1986).

Statistical analysis of behavioral and ERP data were performed using SPSS and Neuroscan software (Neuroscan Labs, El Paso, TX). Mean reaction times (RT) and error percentages were tested separately for word and non-word targets using an analysis of variance for repeated measures with Overlap (alliterating vs. unrelated) as within-subject, and Group as between-subjects factor. Post hoc $t$ tests (least significance difference, LSD) were performed only when main effects reached significance or two factors interacted significantly.
Experimental ERP effects were assessed separately for each subject group using mean amplitude values in the time windows corresponding to prominent ERP components in the group grand averages. For ERPs prior to the N400, time windows were selected separately for each subject group by computing individual peak scores and taking the minimum and maximum latency values of these peak scores. In preschoolers, the first prominent negative peak was labeled $\mathrm{N}_{200}$, according to its mean latency (for a similar approach see Shafer et al., 2000). In beginning readers the two early negativities were labeled N1 and N2. Three consecutive $100 \mathrm{~ms}$ windows were selected to assess N400 effects (for a similar approach see Perrin and Garcia-Larrea, 2003). The resulting time windows were as follows, pre-schoolers: P1, 90-120 ms; $\mathrm{N}_{200}, 170-225 \mathrm{~ms}$; beginning readers: P1, 90-110 ms; N1, 120-170 ms; N2, 250-350 ms. The 3 consecutive $\mathrm{N} 400$ windows for all children were N400a: 450-550 ms; N400b: 550-650 ms; N400c: 650-750 ms. For adults latencies were earlier: P1: 40-70 ms; N1: 105-140 ms; N400a: 300-400 ms; N400b: 400-500 ms; N400c: 500-600 ms.

For further analysis, we selected electrodes in which the ERP components are most frequently reported to occur, as we did not investigate underlying sources or topographical differences between groups. This selection was further corroborated by visual inspection of our data (see Figs. 2-6). Thus, as the early components are typically reported for vertex, or fronto-central sites (e.g. Kraus et al., 1993; Sharma et al., 1997; Takeshita et al., 2002), P1, N1, N200, and $\mathrm{N} 2$ effects were tested on $\mathrm{Fz}, \mathrm{FCz}$ and $\mathrm{Cz}$. As previous literature indicated a more posterior and lateralized predominance for the phonological N400 effect (Rugg, 1984), Fz, Cz, Pz, T3 and T4 were included when testing priming effects in the N400 time windows. For each subject group, separate analyses of variance for repeated measures were carried out on mean amplitudes for word and non-word targets with Overlap (unrelated vs. alliterating) and Electrode as within-subject variables. Because of large group differences in component morphology and latencies we did not perform an analyses with Group as betweensubjects factor. We only report results reaching significance at $P<0.05$ after Geisser-Greenhouse correction.

\section{Results}

\subsection{Experiment 1: word primes}

In the first experiment, subjects performed a lexical decision task, responding to word/non-word targets which were preceded by word primes. The word primes were either unrelated or shared the initial two phonemes (i.e. alliterated) with the targets (see Fig. 1a). In this experiment, onset priming effects may result from pre-lexical and/or lexical processing, as word primes involve both levels of processing. 


\section{Word Targets}

(a) pre-schoolers

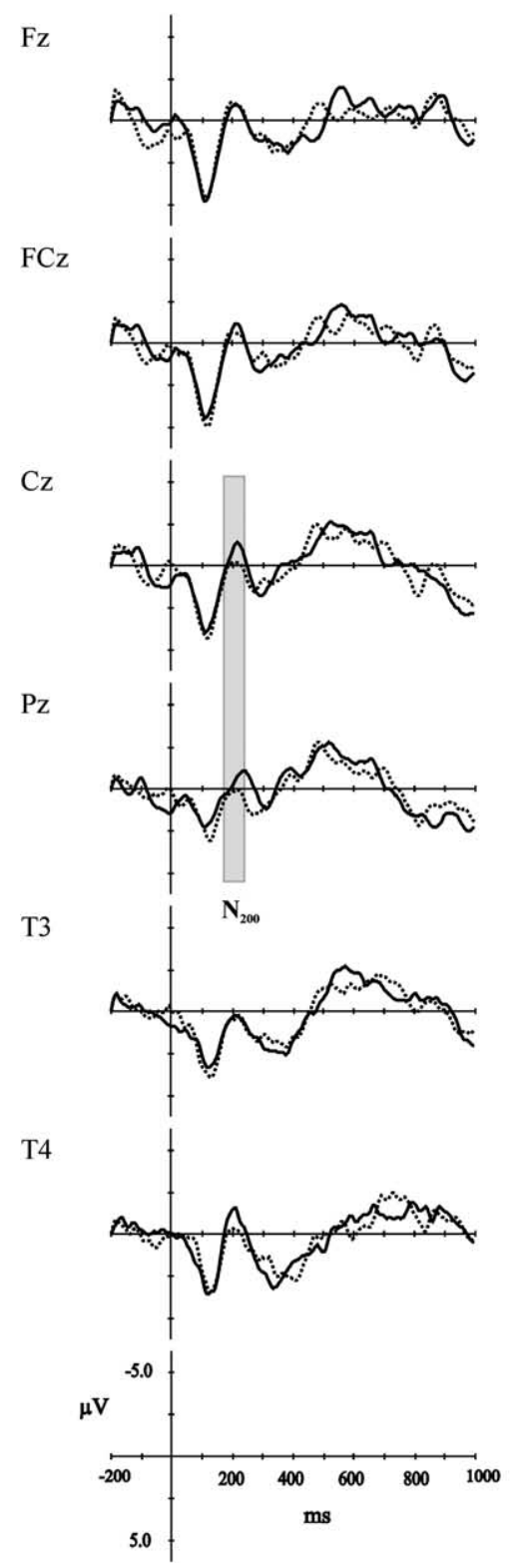

(b) beginning readers
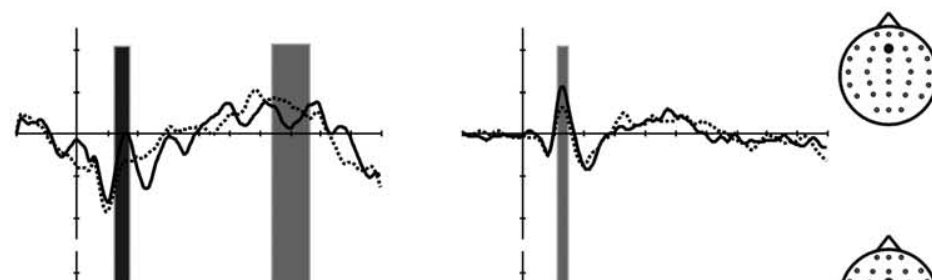

Fig. 2. Grand average ERP waveforms for word targets in Expt. 1 (word primes), for (a) pre-schoolers, (b) beginning readers, and (c) adults, for midline (Fz, FCz, Cz, Pz), left (T3), and right (T4) hemisphere electrodes.

\subsubsection{Behavioral measures}

3.1.1.1. Error rates. All subjects performed the task accurately with error rates below or around $10 \%$ (see Table 2), indicating that even the youngest participants were able to accurately perform our experimental task. For word targets, there was a significant Group difference $(F(2,24)=8.6 ; P<0.005)$ and a significant Overlap $\times$ Group $(\mathrm{F}(2,24)=3.9 ; P<0.05)$ interaction. As for the overall Group effect, post hoc $t$ tests indicated that pre-schoolers made more errors than beginning readers $(P<0.005)$ and adults $(P<0.005)$, but beginning readers did not differ from adults $(P=0.87)$. The Overlap $\times$ Group interaction was due to nonsignificant trends towards more errors in case of alliterating word targets for pre-schoolers and more errors in case of unrelated word targets for both beginning readers and adults. The same analyses for nonword targets did not yield any significant effect. 


\section{Nonword Targets}

(a) pre-schoolers

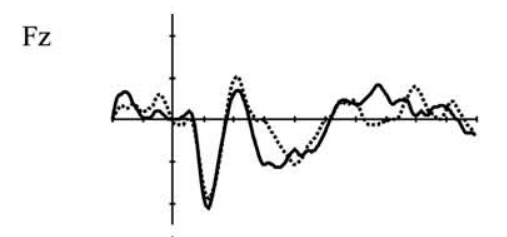

$\mathrm{FCz}$

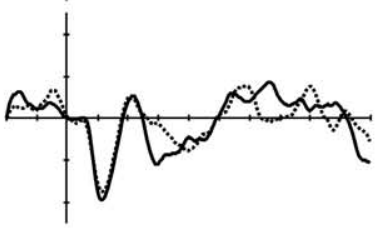

$\mathrm{Cz}$

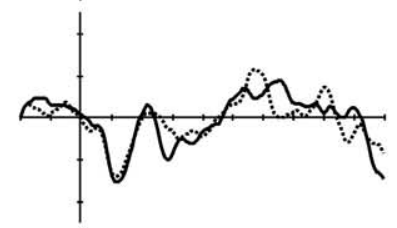

$\mathrm{Pz}$

$\mathrm{T} 4$

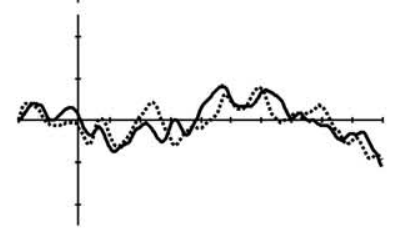

T3
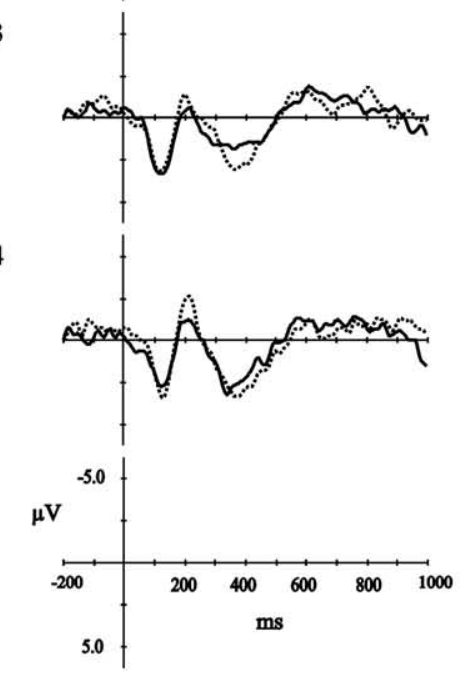

(b) beginning readers
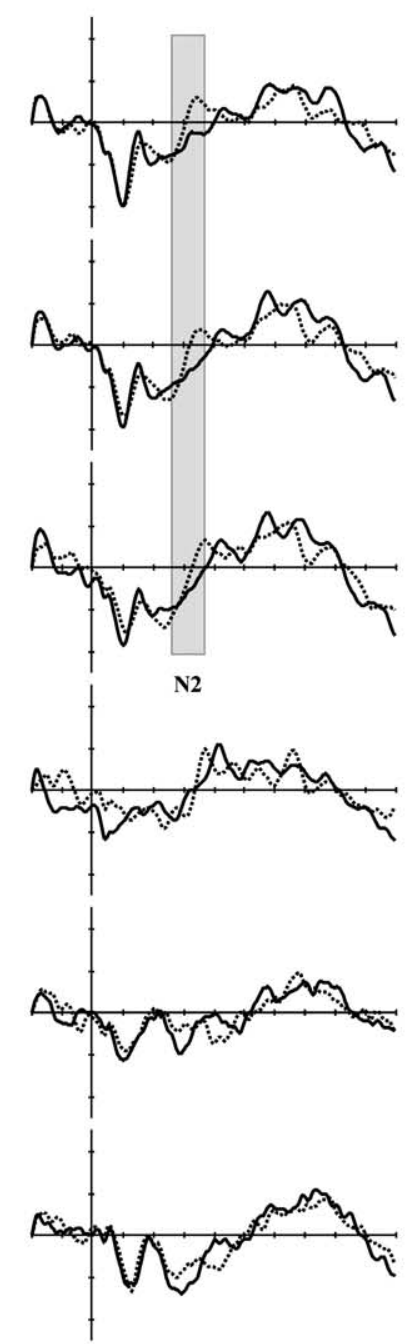

p-values

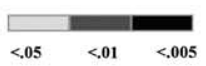

(c) adults
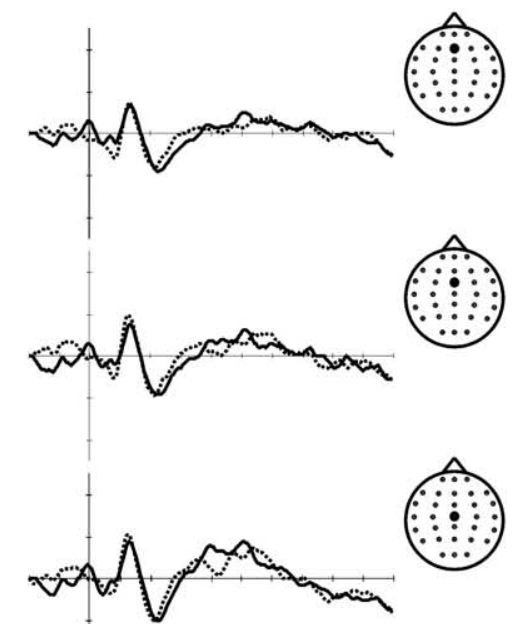

Fig. 3. Grand average ERP waveforms for non-word targets in Expt. 1 (word primes), for (a) pre-schoolers, (b) beginning readers, and (c) adults, for midline (Fz, FCz, Cz, Pz), left (T3), and right (T4) hemisphere electrodes.

3.1.1.2. Reaction times. RT analysis (see Table 2) yielded significant main effects of Group for word $(F(2,24)=10.8$; $P=0.000)$ and non-word targets $(F(2,24)=9.9$; $P<0.005)$. Post hoc $t$ tests showed that RTs of preschoolers and beginning readers did not differ significantly for word $(P=0.21)$, or non-word targets $(P=0.56)$, but both groups were significantly slower than adults for word $(P=0.000$ and $P=0.005)$ and non-word targets $(P=0.000$ and $P=0.005)$. There were no significant effects of Overlap.

\subsubsection{Developmental differences in ERP morphology, amplitude and latency}

ERP waveforms elicited by word targets are given in Fig. 2. ERP morphology showed clear age differences between groups (see also Fig. 6). Word targets elicited a typical P1-N1-P2-N400 pattern in adults, with a biphasic N400 over fronto-central electrodes. Beginning readers showed a comparable ERP morphology, but also an additional negativity at a latency around $300 \mathrm{~ms}$ present at fronto-central electrodes, which we will refer to as $\mathrm{N} 2$. 


\section{Word Targets}

(a) pre-schoolers

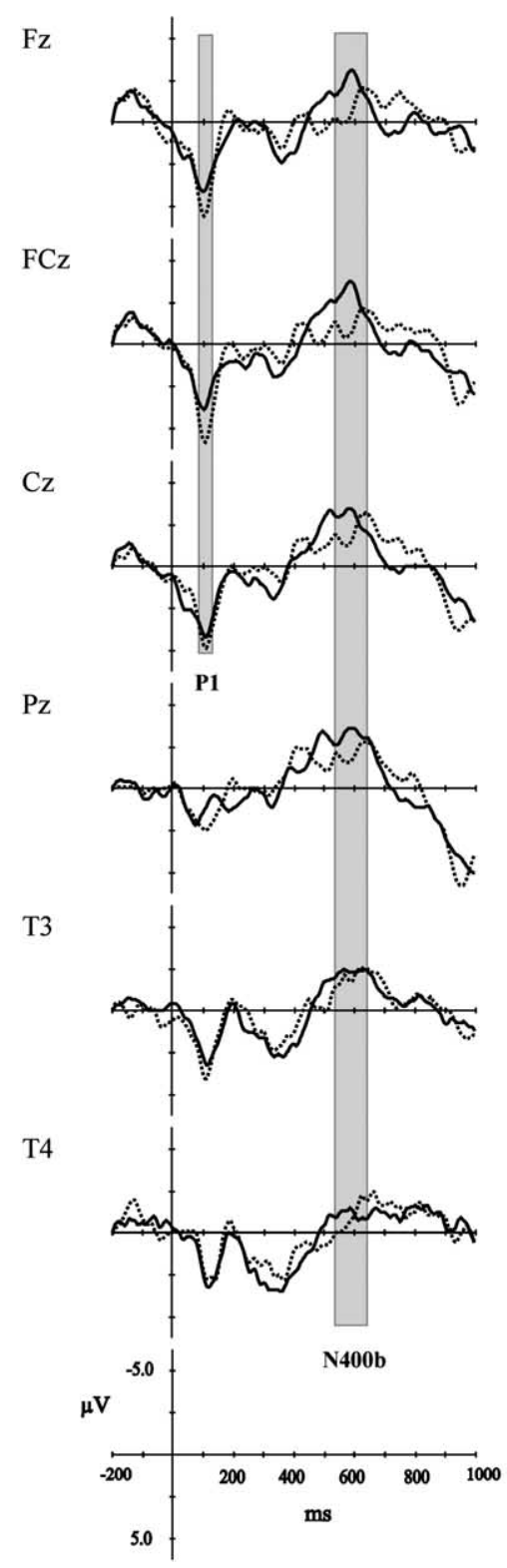

(b) beginning readers
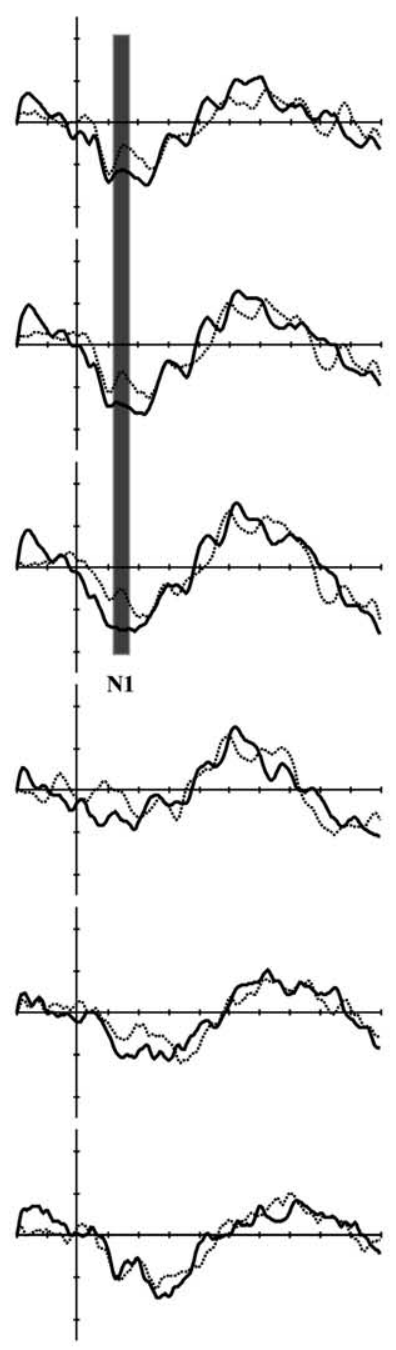

p-values

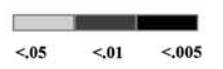

(c) adults

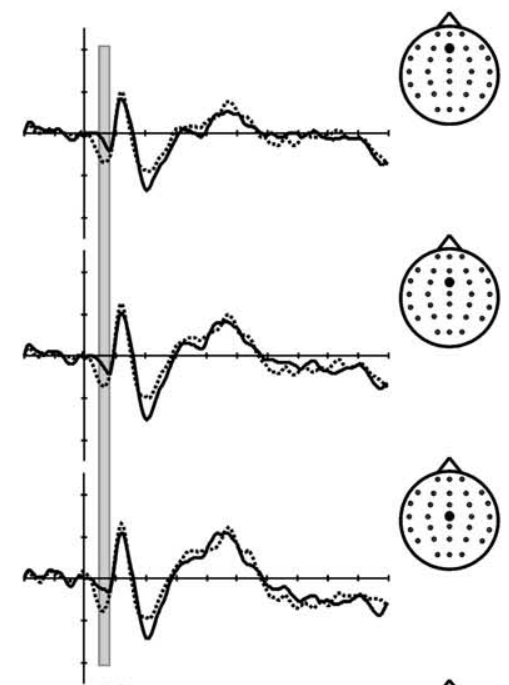

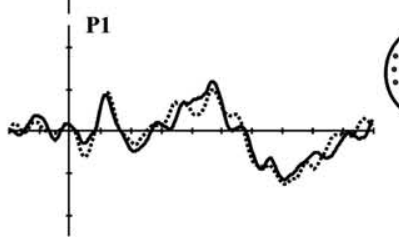

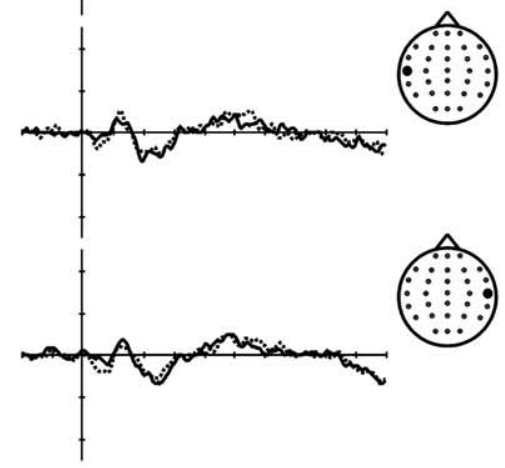

- Unrelated

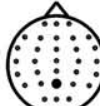

Fig. 4. Grand average ERP waveforms for word targets in Expt. 2 (non-word primes), for (a) pre-schoolers, (b) beginning readers, and (c) adults, for midline (Fz, FCz, Cz, Pz), left (T3), and right (T4) hemisphere electrodes.

Pre-schoolers showed a biphasic positive-negative complex, which we will refer to as $\mathrm{P} 1-\mathrm{N}_{200}$, and a subsequent $\mathrm{N} 400$. In addition to these morphological differences, visual inspection of the data revealed longer latencies for corresponding ERP components in children vs. adults, i.e. P1, and N400, and in beginning readers vs. adults, i.e. N1. Furthermore, P1 amplitude was larger in children than in adults.

\subsubsection{Phonological priming effects: word targets}

Adults (Fig. 2c) showed a phonological priming effect on the $\mathrm{N} 1$, i.e. alliterating word targets elicited a reduced N1 response as compared to unrelated word targets $(F(1,7)=11.0 ; P<0.025)$. Adults did not show significant effects of phonological priming on any of the other ERP components.

Beginning readers (Fig. 2b) also showed phonological priming on the N1. Like in adults, the N1 was smaller for alliterating vs. unrelated word targets $(F(1,7)=18.5$; $P<0.005)$. Additionally, beginning readers showed a rather late priming effect in the $\mathrm{N} 400 \mathrm{c}$ window, with an increased N400 amplitude to alliterating word targets $(F(1,7)=13.3 ; P<0.01)$. 


\section{Nonword Targets}

(a) pre-schoolers

Fz

$\mathrm{FCz}$

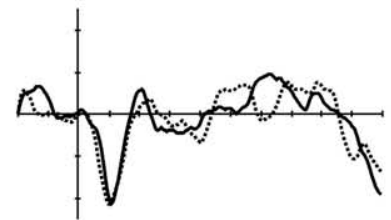

$\mathrm{Cz}$

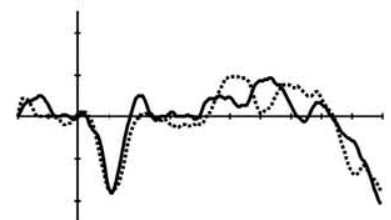

$\mathrm{Pz}$

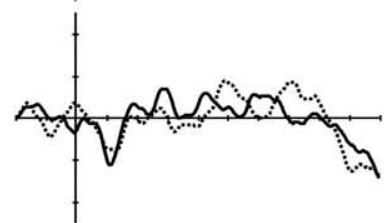

$\mathrm{T} 3$

$\mathrm{T} 4$
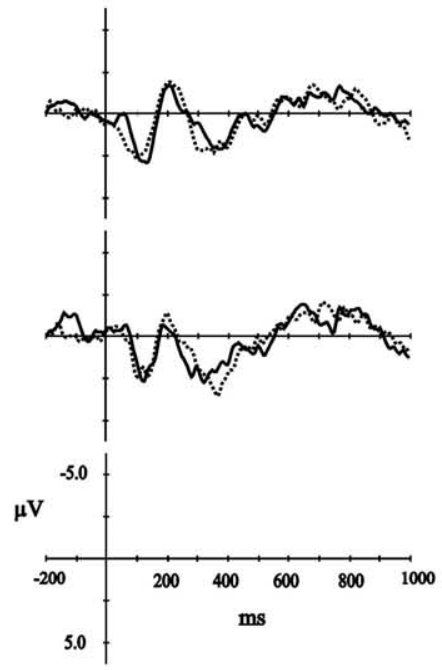

(b) beginning readers
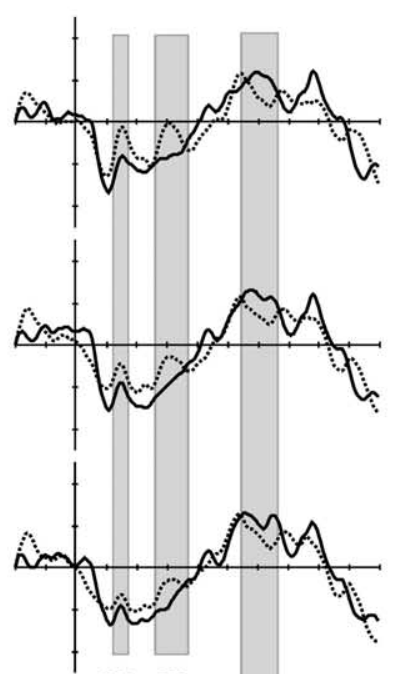

N1 N2
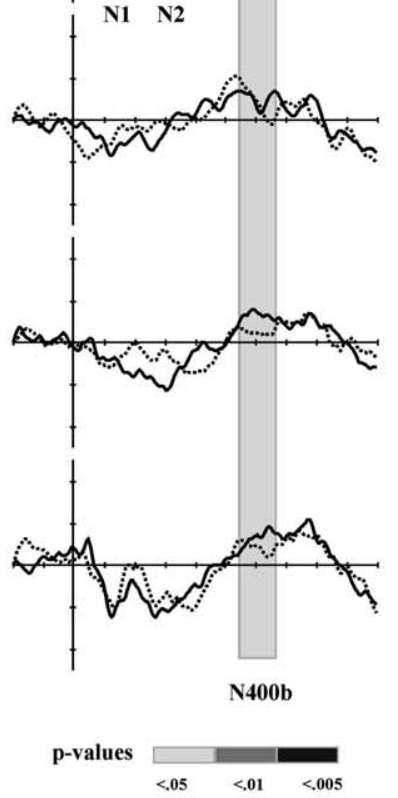

(c) adults
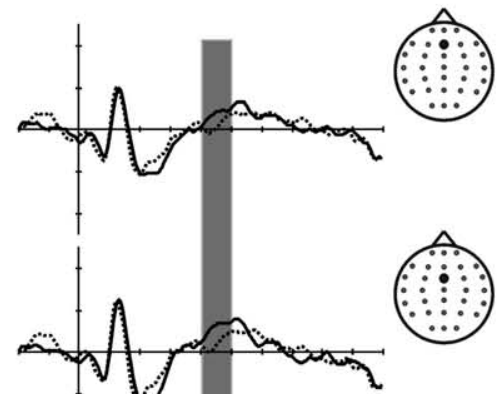

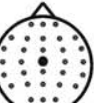<smiles></smiles>
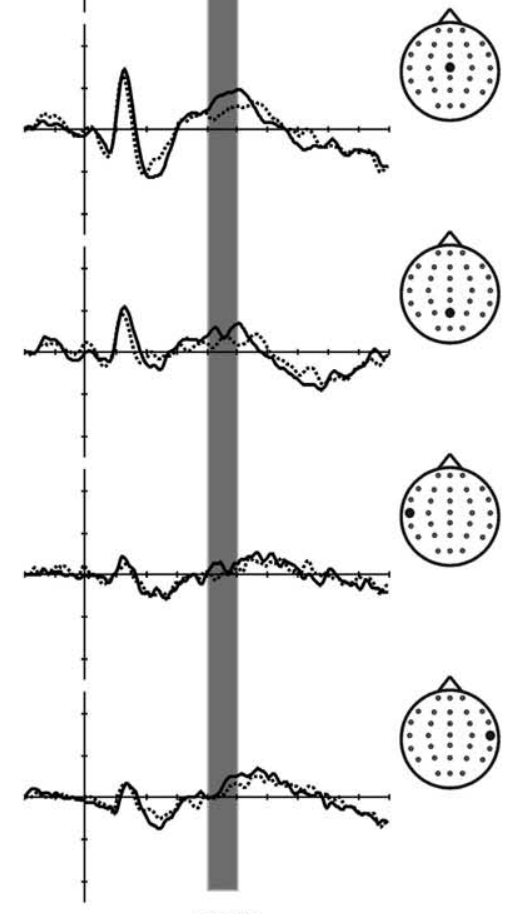

N400b

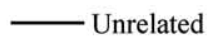

............. Alliterating

Fig. 5. Grand average ERP waveforms for non-word targets in Expt. 2 (non-word primes), for (a) pre-schoolers, (b) beginning readers, and (c) adults, for midline (Fz, FCz, Cz, Pz), left (T3), and right (T4) hemisphere electrodes.

Pre-schoolers (Fig. 2a) showed a reduced $\mathrm{N}_{200}$ to alliterating as compared to unrelated word targets. This $\mathrm{N}_{200}$ reduction did not show a significant effect over the 3 central electrodes $(F(1,10)=1.6$; not significant $)$, but it was significant $(P<0.05)$ when tested at electrodes $\mathrm{Cz}$, and $\mathrm{Pz}$ where the effect was also most clearly visible (see Fig. 2a). Pre-schoolers did not show significant effects of phonological priming in any of the 3 N400 windows.

\subsubsection{Phonological priming effects: non-word targets}

ERP responses to non-word targets are given in Fig. 3. In all subject groups, ERP morphology in response to non-word targets was comparable to that elicited by word targets. Overall the ERP signal to non-word targets showed a relatively large variability. The phonological priming effect in the N400c window as shown to word targets by beginning readers, was not present with non-word targets, neither were the $\mathrm{N} 1 / \mathrm{N}_{200}$ effects as shown to word targets by all subject groups. The only 

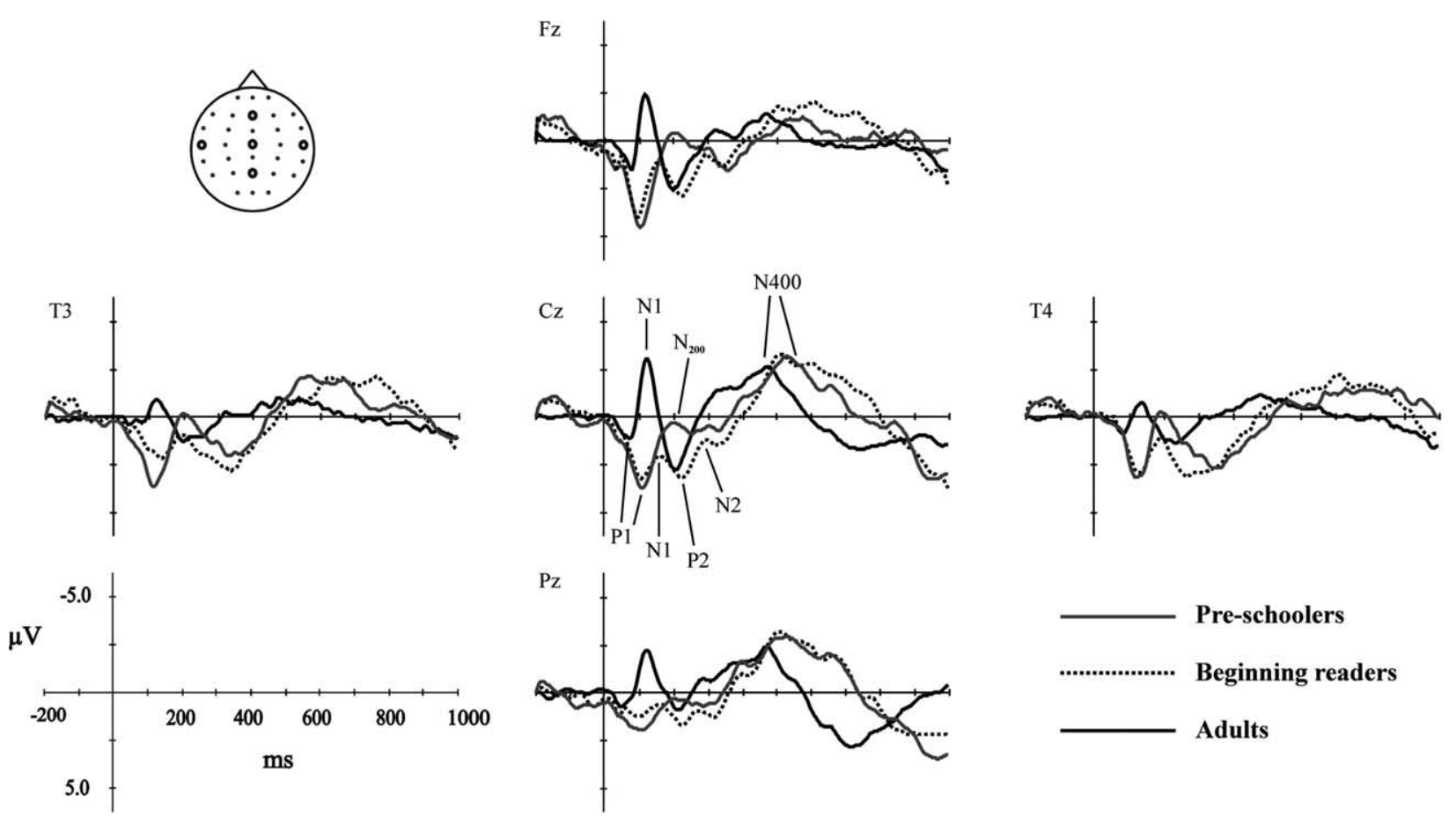

Fig. 6. Grand average ERP waveforms of word targets (collapsed over Expts. 1 and 2) for all 3 subject groups.

significant phonological priming effect on ERPs to non-word targets, was an enhanced N2 response due to alliteration in beginning readers $(F(1,7)=7.4 ; P<0.05)$.

\subsection{Experiment 2: non-word primes}

In the second experiment, subjects performed the same lexical decision task as in Expt. 1, but primes were alliterating or unrelated non-words instead of words (see Fig. 1b). In this experiment, onset priming effects were expected to result from pre-lexical processing as non-word primes do not have a lexical representation. Thus, if the late enhanced $\mathrm{N} 400 \mathrm{c}$ for beginning readers and the $\mathrm{N} 1 / \mathrm{N}_{200}$ reductions to alliterating word targets in Expt. 1, in fact reflect developmental differences in lexical organization, they should not be replicated in Expt. 2. If these ERP priming effects reflect phonological processing independent of the lexical status of the primes, the ERP results of Expt. 2 are expected to replicate those of Expt. 1.

\subsubsection{Behavioral measures}

3.2.1.1. Error rates. All subjects performed the task accurately with error rates below or around 10\% (see Table 3). Word targets showed significant main effects of Overlap $\quad(F(1,20)=5.0 ; \quad P<0.05), \quad$ and Group $(F(2,20)=6.1 ; P<0.01)$. Post hoc $t$ tests indicated that error percentages of pre-schoolers were significantly higher than those of beginning readers $(P<0.025)$ and adults $(P<0.005)$. Beginning readers and adults did not differ significantly $(P=0.45)$. As can be seen in Table 3, the main effect of Overlap was due to an overall, higher error percentage for alliterating as compared to unrelated word

Table 2

Mean (SEM) of RTs in milliseconds and error percentages, for pre-schoolers, beginning readers and adults in Expt. 1

\begin{tabular}{|c|c|c|c|c|c|}
\hline & \multicolumn{5}{|l|}{ Mean RT \% error } \\
\hline & Preschoolers $(n=11)$ & \multicolumn{2}{|c|}{ Beginning readers $(n=8)$} & \multicolumn{2}{|c|}{ Adults $(n=8)$} \\
\hline \multicolumn{6}{|l|}{ Word targets } \\
\hline Alliterating & 1494 (101) $12.5(2.2)$ & $1350(113)$ & $4.1(0.5)$ & $881(57)$ & $3.4(0.8)$ \\
\hline Unrelated & $1502(101) \quad 9.1(1.7)$ & $1304(105)$ & $5.0(1.1)$ & $904(67)$ & $5.0(0.7)$ \\
\hline Overall & $1497(98) \quad 10.8(1.8)$ & 1327 (109) & $4.5(0.6)$ & $893(62)$ & $4.2(0.6)$ \\
\hline \multicolumn{6}{|c|}{ Non-word targets } \\
\hline Alliterating & $1526(101) \quad 4.1(1.4)$ & $1441(100)$ & $2.8(0.7)$ & $980(66)$ & $3.0(0.6)$ \\
\hline Unrelated & $1550(99)$ & 1467 (124) & $4.1(1.2)$ & $960(65)$ & $3.0(0.9)$ \\
\hline Overall & $1537(98)$ & $1454(112)$ & $3.4(0.7)$ & $970(65)$ & $3.0(0.7)$ \\
\hline
\end{tabular}


Mean (SEM) of RTs in milliseconds and error percentages, for pre-schoolers, beginning readers and adults in Expt. 2

\begin{tabular}{|c|c|c|c|c|c|}
\hline & \multicolumn{5}{|l|}{ Mean RT \% error } \\
\hline & Preschoolers $(n=8)$ & \multicolumn{2}{|c|}{ Beginning readers $(n=8)$} & \multicolumn{2}{|c|}{ Adults $(n=7)$} \\
\hline \multicolumn{6}{|l|}{ Word targets } \\
\hline Alliterating & $1461(116) 10.1(1.5)$ & 1373 & $4.1(1.1)$ & $817(22)$ & $3.4(0.5)$ \\
\hline Unrelated & $1401(83) \quad 6.5(1.2)$ & $1366(137)$ & $4.3(1.5)$ & $815(18)$ & $2.5(1.4)$ \\
\hline Overall & $1431(99) \quad 8.3(1.1)$ & $1370(135)$ & $4.2(1.3)$ & $816(19)$ & $3.0(0.9)$ \\
\hline \multicolumn{6}{|c|}{ Non-word targets } \\
\hline Alliterating & $1618(120) \quad 5.2(1.1)$ & $1447(132)$ & $3.2(1.1)$ & $901(24)$ & $1.7(0.5)$ \\
\hline Unrelated & $1603(137) \quad 3.9(2.3)$ & $1471(150)$ & $3.0(0.9)$ & $873(26)$ & $1.4(0.6)$ \\
\hline Overall & 1611 (127) 4.5 (1.6) & $1459(141)$ & $3.1(0.9)$ & $887(24)$ & $1.6(0.4)$ \\
\hline
\end{tabular}

targets. The same analyses for non-word targets did not yield any significant effect.

3.2.1.2. Reaction times. RT analysis (see Table 3) yielded significant main effects of Group for word $(F(2,20)=10.6$; $P<0.005)$ and non-word targets $(F(2,20)=10.5$; $P<0.005)$. Post hoc $t$ tests showed that RTs of preschoolers and beginning readers did not differ significantly for word $(P=0.67)$, or non-word targets $(P=0.35)$, but both groups were significantly slower than adults for word $(P=0.000$ and $P<0.005)$ and non-word targets $(P=0.000$ and $P<0.005)$. Separate within-group analyses did not show any significant RT effects for word or nonword targets.

\subsubsection{Developmental differences in ERP morphology, amplitude and latency}

ERP waveforms elicited by word targets are given in Fig. 4. Word targets elicited the same ERP components and showed the same group differences in ERP morphology and latency as reported in Expt. 1.

\subsubsection{Phonological priming effects: word targets}

As for ERP effects of word onset priming, visual inspection of the data (Fig. 4) indicated that neither the enhanced $\mathrm{N} 400 \mathrm{c}$ elicited by alliterating word targets in beginning readers, nor the early $\mathrm{N} 1 / \mathrm{N}_{200}$ reductions to word targets as shown by all groups in Expt. 1, were replicated in Expt. 2.

In adults (Fig. 4c), a comparison of the two overlap conditions indicated a very early P1 amplitude difference. The priming effect, a larger $\mathrm{P} 1$ to alliterating as compared to unrelated word targets, was significant $(F(1,6)=9.2$; $P<0.025)$. Later ERP components did not show any significant effects.

In beginning readers (Fig. 4b), alliterating word targets elicited a larger $\mathrm{N} 1$ than unrelated word targets $(F(1,7)=12.9 ; \quad P<0.01)$. Beginning readers did not show onset priming effects on the P1. Although the $\mathrm{N} 400 \mathrm{~b}$ window indicated some amplitude reduction to alliterating word targets, this effect did not reach significance.

Pre-schoolers (Fig. 4a), showed a larger P1 to alliterating as compared to unrelated word targets $(F(1,7)=9.2$; $P<0.025)$. Whereas in pre-schoolers this early priming effect occurred as a P1 difference, its latency range was similar to that of the N1 priming found for beginning readers. Pre-schoolers also showed an effect of Overlap in the N400b window $(F(1,7)=8.3 ; P<0.025)$ : alliterating word targets elicited a reduced negativity.

\subsubsection{Phonological priming effects: non-word targets}

ERP responses to non-word targets are given in Fig. 5. Like in Expt. 1, ERP morphology in response to non-word targets was comparable to the ERP elicited by word targets, but showed considerably more variability. Phonological priming did not lead to any significant effects in preschoolers. Beginning readers showed both an enhanced N1 $(F(1,7)=5.9 ; P<0.05)$ and an enhanced $\mathrm{N} 2$ amplitude $(F(1,7)=7.1 ; P<0.05)$ to alliterating as compared to unrelated non-word targets. In the N400b window, both beginning readers and adults showed a significantly reduced amplitude to alliterating non-word targets $(F(1,7)=8.9$; $P<0.025$, and $F(1,6)=14.5 ; P<0.01)$.

\section{Discussion}

We studied the development of spoken word recognition in early school years as reflected by phonological onset priming effects on ERP responses to words and non-words in an auditory lexical decision task. Our ERP recordings presented age-dependent patterns of responses that provide evidence for structural differences of ERPs in pre-schoolers, beginning readers and adults (see Section 4.1). The most prominent effects of phonological onset priming were an enhanced N400c amplitude to alliterating word targets with word primes in beginning readers, and typical phonological N400 reductions with non-word primes in all groups. Onset priming also influenced ERP components in earlier time windows, with opposite effects for word (i.e. N1/ $\mathrm{N}_{200}$ 
reduction) and non-word primes (i.e. P1/N1 enhancement) in all groups. These electrophysiological modulations and their age-(in)dependency seem to be related to maturational levels of the subject's lexical system (see Sections 4.2 and 4.3).

\subsection{Developmental changes in ERP morphology, amplitude and latency}

Word and non-word targets elicited a P1-N1-P2-N400 pattern in adults, a P1-N1-P2-N2-N400 pattern in beginning readers and a $\mathrm{P} 1-\mathrm{N}_{200}-\mathrm{N} 400$ pattern in pre-schoolers. These patterns are consistent with previous developmental ERP investigations, in which clicks, tones, and consonant-vowel stimuli were used (e.g. Ceponiene et al., 2002; Csepe, 1995; Kraus et al., 1993; Paetau et al., 1995; Ponton et al., 2000; Shafer et al., 2000; Sharma et al., 1997; Takeshita et al., 2002).

Our data bring additional support to the hypothesis that the $\mathrm{P} 1$, as measured in children, represents a delayed equivalent of the adult P1. The relatively large P1 amplitude in children is also consistent with earlier studies (e.g. Kraus et al., 1993; Sharma et al., 1997). The observed group differences in the morphology of early negativities (see Fig. 6) suggest that maturational ERP changes include not only a general decrease in latency (as it is conventionally assumed), but also additional and more complex structural changes. On a more general level, our findings show that caution is required when the adult ERP literature is used as a reference for interpreting ERP components in children.

As for ERPs in beginning readers, morphology, latency, as well as phonological priming effects suggest that their first negativity reflects a delayed equivalent of the adult N1. The presence of an N1 in 7/8 year old children with a relatively short SOA of $1 \mathrm{~s}$, may seem unexpected considering previous studies (e.g. Bruneau et al., 1997; Ceponiene et al., 1998, 2002). However, in contrast to these previous studies in which subjects passively listened to meaningless auditory (speech) stimuli, our subjects had to actively perform lexical decisions on word and non-word stimuli. As N1 amplitude has been found to increase with attention level (Näätänen and Picton, 1987) and linguistic relevance (Sanders and Neville, 2003a,b), the requirements of our experimental task may have increased the likelihood of recording the N1 in children. It is interesting to note that these same factors did not lead to an obvious N1 in the 5-6year-olds (for a comparable finding in a comparison of 4- vs. 9-year-olds see Ceponiene et al., 2002).

The biphasic N1-N2 pattern in beginning readers may represent an intermediate developmental stage between the early negativities measured in pre-schoolers and adults. The $\mathrm{N}_{200}$ as measured in pre-schoolers revealed some functional similarity with the N1 recorded in both older subject groups (e.g. amplitude reduction to alliterating word targets in Expt. 1). But its long latency and broad peak would suggest that it rather relates to the most consistently reported negativity in children, the N2/N250 (Ceponiene et al., 2002; Takeshita et al., 2002). As the $\mathrm{N}_{200}$ seems to share some characteristics with the $\mathrm{N} 1$ and the child N2, one may hypothesize that age group differences in the shape of these early negativities reflect a continuous development of partly overlapping neural sources involved in acoustic/phonetic processing of speech.

\subsection{ERP correlates of lexical restructuring: N400 effects}

One of the main goals of the present study was to investigate whether developmental changes in lexical access and organization produce measurable ERP manifestations. Importantly, our findings confirmed that the maturational level of the lexical processing system of the different groups is relevant for explaining the observed patterns of ERP effects. In particular, we suggest that the effects shown by beginning readers, and especially their late $\mathrm{N} 400 \mathrm{c}$ enhancement to alliterating word targets in Expt. 1, may be related to the peculiarity of the maturational stage of the lexical system in this age group (Jusczyk, 1993; Metsala and Walley, 1998), i.e. it is undergoing substantial segmental restructuring.

It is worth remarking that this group-specific N400c effect was only present when word targets were preceded by alliterating word primes. Moreover, this effect was opposite to the typical phonological N400 effect, observed when subjects attend to the phonological aspects of the task (Grossi et al., 2001; Perrin and Garcia-Larrea, 2003; Praamstra et al., 1994; Radeau et al., 1998; Rugg, 1984). These considerations suggest that this N400c enhancement does not reflect the typical processing of phonological discordance. Rather, they indicate that, in beginning readers, alliterating word primes increase rather than decrease the neural processing required for word target recognition. Furthermore, they suggest that this effect may occur at a lexical level.

In beginning readers, as a result of both vocabulary growth (Metsala and Walley, 1998) and acquisition of reading (Goswami et al., 2003; Liberman, 1973; Morais et al., 1986), the lexical system is undergoing substantial segmental restructuring. This restructuring possibly involves remarkable changes in the contribution of word onset information to lexical processing. It is thus possible that in beginning readers, compared to adults, lexical operations are slower and sub-optimal and that, at the prime-target SOA used in the present study, lexical processing of the word target can be influenced by residual processing of the word prime.

In adults, behavioral evidences suggest that, in conditions which hamper word recognition (e.g. word identification in noise), alliterating word primes inhibit RTs to word targets (Zwitserlood, 1994). Based on a cohort-model, these effects are usually explained in terms of an increased processing effort related to lexical competition during lexical access and selection (Marslen-Wilson, 1987). 
A similar situation may be present in our experiment for beginning readers, which would predict their effortful lexical processing of alliterating word targets and consequently, the functionally related N400c enhancement.

This interpretation also predicts longer RTs to alliterating word prime-word target pairs in beginning readers. In a previous behavioral study with the same experimental design, and partly the same subjects, we found such an inhibition of RTs to be significant in the same age group (Blomert and Bonte, 2002). Similarly, in the present study, a trend toward the same effect was present but it did not reach significance (see Table 2). The smaller size of the sample and the overall increase in RTs of children performing the task in the ERP recording setting may have compromised the detection of the expected effect. Furthermore, it should be considered that behavioral phonological priming effects in lexical decision tasks are intrinsically small, as they tend to be obscured by additional post-lexical strategic processes associated with decision making (Chumbley and Balota, 1984). Our ERP results show that the N400, which reflects primarily word-based processing (Kounios and Holcomb, 1992), might be a sensitive marker for these phonological priming effects.

Under the same experimental conditions alliteration did not elicit a similar N400 enhancement in adults and preschoolers. In adults, this is presumably due to a fast and automatized lexical processing of word primes. In preschoolers, on the other hand, a more holistic lexical system may process word onset information differently (Walley, 1988).

In Expt. 2, effects of non word primes were expected to result from pre-lexical phonological levels of processing. In this experiment, alliterating non-word primes led to a reduced negativity that seems to gradually disappear with age, i.e. it is strong in pre-schoolers, weak in beginning readers, and absent in adults (see Fig. 4). This developmental change suggests that with age, late phonological/ lexical aspects of spoken word recognition become less prone to pre-lexical effects of onset priming as elicited by alliterating non-word primes. In the case of non-word targets, beginning readers and adults showed a typical phonological N400 effect (i.e. N400 reduction due to alliteration). This confirms previous findings indicating that the phonological $\mathrm{N} 400$ effect tends to be better detectable when it is not occluded by concomitant and effortful semantic processing of words (Perrin and GarciaLarrea, 2003). The lack of a similar effect in pre-schoolers is likely due to this group's large variability of the ERP signal in the N400 time-window, probably reflecting the fact that these children used a variety of different strategies to process non-words.

\subsection{Phonological priming in early time windows}

In all subject groups, alliteration also modulated word target ERPs prior to the $\mathrm{N} 400$, i.e. the $\mathrm{P} 1$ and/or $\mathrm{N} 1 / \mathrm{N}_{200}$, indicating that phonological priming started to exert its effect already at the level of acoustic/phonetic processing. These priming effects support recent ERP findings which indicated that neural generators underlying the N1 may be specifically involved in the processing of word onsets (Sanders and Neville, 2003a,b). Furthermore, the opposite priming effects in Expts. 1 and 2 may suggest that the acoustic/phonetic processing of word onsets was differentially affected by word vs. non-word primes. These opposite priming effects dependent on the lexical status of the primes, might imply that already at a very early stage, processing of speech sounds does not only rely on acoustic complexity but also depends on language experience or expectancy (Liebenthal et al., 2003). However, because similar effects were not present when targets were nonwords, these results should be interpreted with caution. Further experiments, using e.g. identical target stimuli in a cross-linguistic comparison between native and non-native listeners are required to verify and confirm our current interpretation.

Group differences in early priming effects may reflect further developmental changes in word onset processing. Again, several findings indicate relatively strong onset priming effects for beginning readers as compared to both other age groups. For example, unlike both other groups, beginning readers showed an N1 enhancement to alliterating word as well as non-word targets in Expt. 2, and a similarly enhanced $\mathrm{N} 2$ to alliterating non-word targets in both experiments. These N1/N2 enhancements may reflect comparable increases in neural response due to alliteration when primes and/or targets consisted of non-word stimuli.

The N1 reduction to alliterating word targets in Expt. 1, as shown by both beginning readers and adults, may indicate similar early processing of word initial information. The weak and delayed $\mathrm{N}_{200}$ reduction in pre-schoolers, suggests relatively slow and possibly different processing of word onsets. These findings may further corroborate the idea that in pre-schoolers, word-initial information does not yet have the same status in the process of word recognition, as suggested for adults and older children (e.g. Walley, 1988).

\section{Conclusion}

Our data show that ERPs elicited by spoken words undergo substantial changes during early school years, even in a period as short as 2 years. Developmental changes in ERP morphology and latency may reflect an increase in speed and efficiency of neural processes necessary for word recognition.

The distinct pattern of priming effects on ERPs in our age groups support the view that the system subserving the recognition of spoken words undergoes a substantial restructuring of processing and representation of phonological information. Most importantly, our ERP results indicate distinct processing of word onsets in beginning 
readers, suggesting that vocabulary growth and the acquisition of reading critically contribute to the formation of a fully segmental lexical system that capitalizes on wordinitial phonological information.

In conclusion, our study indicates that phonological priming in combination with ERP measurements provides a useful framework for investigating developmental changes in language comprehension. In future studies, the sensitivity of distinct ERP components to the manipulation of phonological information in this context may also help in investigating phonological processing anomalies in developmental language disorders such as developmental dyslexia.

\section{Acknowledgements}

The authors are grateful to Elia Formisano, Lisa Jonkman, Bernadette Jansma and two anonymous reviewers for useful comments on the manuscript. This work was partially supported by SWOL.

\section{References}

Ackermann H, Lutzenberger W, Hertrich I. Hemispheric lateralization of the neural encoding of temporal speech features: a whole-head magnetencephalography study. Cogn Brain Res 1999;7:511-8.

Annett M. Family handedness in three generations predicted by the right shift theory. Ann Hum Genet 1979;42:479-91.

Bleichrodt N, Drenth PJD, Zaal JN, Resing WCM. Revisie Amsterdamse Kinder Intelligentie Test. Instructie, normen, psychometrische gegevens. Lisse: Swets \& Zeitlinger; 1984.

Blomert L, Bonte ML. Brain correlates of pre-lexical and lexical phonological processing in dyslexia. 9th annual meeting of the Cognitive Neuroscience Society, San Francisco, April 2002. 2002.

Bruneau N, Gomot M. Auditory evoked potentials (N1 wave) as indices of cortical development. In: Garreau B, editor. Neuroimaging in child neuropsychiatric disorders. Berlin: Springer; 1998. p. 113-24.

Bruneau N, Roux S, Guerin P, Barthelemy C, Lelord G. Temporal prominence of auditory evoked potentials (N1 wave) in 4-8-year-old children. Psychophysiology 1997;34:32-8.

Brus BT, Voeten MJM. Een-Minuut-Test. Lisse: Swets \& Zeitlinger; 1999.

Ceponiene R, Cheour M, Näätänen R. Interstimulus interval and auditory event-related potentials in children: evidence for multiple generators. Electroenceph clin Neurophysiol 1998;108:345-54.

Ceponiene R, Rinne T, Naatanen R. Maturation of cortical sound processing as indexed by event-related potentials. Clin Neurophysiol 2002;113:870-82.

Chumbley JI, Balota DA. A word's meaning affects the decision in lexical decision. Mem Cognit 1984;12:590-606.

Connolly JF, Phillips NA. Event-related potential components reflect phonological and semantic processing of the terminal word of spoken sentences. J Cogn Neurosci 1994;6:256-66.

Csepe V. On the origin and development of the mismatch negativity. Ear Hear 1995;16:91-104.

Eggermont JJ, Ponton CW. The neurophysiology of auditory perception: from single units to evoked potentials. Audiol Neurootol 2002;7: 71-99.

Eulitz C, Diesch E, Pantev C, Hampson S, Elbert T. Magnetic and electric brain activity evoked by the processing of tone and vowel stimuli. J Neurosci 1995;15:2748-55
Garlock VM, Walley AC, Metsala JL. Age-of-acquisition, word frequency, and neighborhood density effects on spoken word recognition by children and adults. J Mem Lang 2001;45:468-92.

Ghyselinck M, de Moor W, Brysbaert M. Age-of-acquisition ratings for 2816 Dutch four- and five-letter nouns. Psychol Belg 2000;40: $77-98$.

Goswami U, Ziegler JC, Dalton L, Schneider W. Nonword reading across orthographies: how flexible is the choice of reading units? Appl Psychol 2003;24:235-47.

Grossi G, Coch D, Coffey Corina S, Holcomb PJ, Neville HJ. Phonological processing in visual rhyming: a developmental ERP study. J Cogn Neurosci 2001;13:610-25.

Hagoort P, Brown CM. ERP effects of listening to speech: Semantic ERP effects. Neuropsychologia 2000;38:1518-30.

Helenius P, Salmelin R, Service E, Connolly JF, Leinonen S, Lyytinen H. Cortical activation during spoken-word segmentation in nonreadingimpaired and dyslexic adults. J Neurosci 2002;22:2936-44.

Jusczyk PW. From general to language-specific capacities: The WRAPSA model of how speech perception develops. J Phonet 1993;21:3-28.

Jusczyk PW. How infants begin to extract words from speech. Trends Cogn Sci 1999;3:323-8.

Kounios J, Holcomb PJ. Structure and process in semantic memory: evidence from event-related brain potentials and reaction times. J Exp Psychol Gen 1992;121:459-79.

Kraus N, McGee T, Carrell T, Sharma A, Micco A, Nicol T. Speech-evoked cortical potentials in children. J Am Acad Audiol 1993;4:238-48.

Kuriki S, Murase M. Neuromagnetic study of the auditory responses in right and left hemispheres of the human brain evoked by pure tones and speech sounds. Exp Brain Res 1989;77:127-34.

Kutas M, Hillyard SA. Reading senseless sentences: brain potentials reflect semantic incongruity. Science 1980;207:203-5.

Kutas M, Van Petten CK. Psycholinguistics electrified: event-related brain potential investigations. In: Gernsbacher MA, editor. Handbook of psycholinguistics. San Diego, CA: Academic Press; 1994. p. 83-143.

Liberman IY. Segmentation of the spoken word and reading acquisition. Bull Orton Soc 1973;23:65-77.

Liebenthal E, Binder JR, Piorkowski RL, Remez RE. Short-term reorganization of auditory analysis induced by phonetic experience. J Cogn Neurosci 2003;15:549-58.

Marslen-Wilson WD. Functional parallelism in spoken word-recognition. Cognition 1987;25:71-102.

Marslen-Wilson W, Warren P. Levels of perceptual representation and process in lexical access: words, phonemes, and features. Psychol Rev 1994;101:653-75.

McQueen JM, Cutler A. Spoken word access processes: an introduction. Lang Cogn Processes 2001;16:469-90.

Metsala JL, Walley AC. Spoken vocabulary growth and the segmental restructuring of lexical representations: precursors to phonemic awareness and early reading ability. In: Metsala JL, editor. Word recognition in beginning literacy. Mahwah, NJ: Lawrence Erlbaum; 1998. p. 89-120.

Morais J, Bertelson P, Cary L, Alegria J. Literacy training and speech segmentation. Cognition 1986;24:45-64.

Näätänen R, Picton T. The N1 wave of the human electric and magnetic response to sound: a review and an analysis of the component structure. Psychophysiology 1987;24:375-425.

Näätänen R, Lehtokoski A, Lennes M, Cheour M, Huotilainen M, Iivonen A, Vainio M, Alku P, Ilmoniemi RJ, Luuk A, Allik J, Sinkkonen J, Alho K. Language-specific phoneme representations revealed by electric and magnetic brain responses. Nature 1997;385:432-4.

Paetau R, Ahonen A, Salonen O, Sams M. Auditory evoked magnetic fields to tones and pseudowords in healthy children and adults. J Clin Neurophysiol 1995;12:177-85.

Pang EW, Taylor MJ. Tracking the development of the N1 from age 3 to adulthood: an examination of speech and non-speech stimuli. Clin Neurophysiol 2000;111:388-97. 
Perrin F, Garcia-Larrea L. Modulation of the N400 potential during auditory phonological/semantic interaction. Cogn Brain Res 2003;17:36-47.

Phillips C, Pellathy T, Marantz A, Yellin E, Wexler K, Poeppel D, McGinnis M, Roberts T. Auditory cortex accesses phonological categories: an MEG mismatch study. J Cogn Neurosci 2000;12: $1038-55$.

Ponton CW, Eggermont JJ, Kwong B, Don M. Maturation of human central auditory system activity: evidence from multi-channel evoked potentials. Clin Neurophysiol 2000;111:220-36.

Praamstra P, Meyer AS, Levelt WJM. Neurophysiological manifestations of phonological processing: latency variations of a negative ERP component timelocked to phonological mismatch. J Cogn Neurosci 1994;6:204-19.

Radeau M, Besson M, Fonteneau E, Castro SL. Semantic, repetition and rime priming between spoken words: behavioral and electrophysiological evidence. Biol Psychol 1998;48:183-204.

Rugg MD. Event-related potentials and the phonological processing of words and non-words. Neuropsychologia 1984;22:435-43.

Sanders LD, Neville HJ. An ERP study of continuous speech processing. I. Segmentation, semantics, and syntax in native speakers. Brain Res Cogn Brain Res 2003a; 15:228-40.

Sanders LD, Neville HJ. An ERP study of continuous speech processing. II. Segmentation, semantics, and syntax in non-native speakers. Brain Res Cogn Brain Res 2003b;15:214-27.

Sanders LD, Newport EL, Neville HJ. Segmenting nonsense: an eventrelated potential index of perceived onsets in continuous speech. Nat Neurosci 2002;5:700-3.

Schaerlaekens A, Kohnstamm D, Lejaegere M. Streeflijst woordenschat voor zesjarigen, 3rd revised ed. Lisse: Swets, \& Zeitlinger; 1999.

Semlitsch HV, Anderer P, Schuster P, Presslich O. A solution for reliable and valid reduction of ocular artifacts, applied to the P300 ERP. Psychophysiology 1986;23:695-703.

Shafer VL, Morr ML, Kreuzer JA, Kurtzberg D. Maturation of mismatch negativity in school-age children. Ear Hear 2000;21:242-51.
Sharma A, Kraus N, McGee TJ, Nicol TG. Developmental changes in P1 and N1 central auditory responses elicited by consonant-vowel syllables. Electroenceph clin Neurophysiol 1997;104:540-5.

Takeshita K, Nagamine T, Thuy DH, Satow T, Matsuhashi M, Yamamoto J, Takayama M, Fujiwara N, Shibasaki H. Maturational change of parallel auditory processing in school-aged children revealed by simultaneous recording of magnetic and electric cortical responses. Clin Neurophysiol 2002;113:1470-84.

Tiitinen H, Sivonen P, Alku P, Virtanen J, Naatanen R. Electromagnetic recordings reveal latency differences in speech and tone processing in humans. Brain Res Cogn Brain Res 1999;8:355-63.

Van Bon WHJ. Taaltest voor kinderen. Lisse: Swets \& Zeitlinger; 1982.

Van den Bos KP, lutje Spelberg HC, Scheepsma AJM, de Vries JR. De klepel. Lisse: Swets \& Zeitlinger; 1999.

Van den Brink D, Brown CM, Hagoort P. Electrophysiological evidence for early contextual influences during spoken-word recognition: N200 versus N400 effects. J Cogn Neurosci 2001;13:967-85.

Van Petten CK, Coulson S, Rubin S, Plante E, Parks M. Time course of word identification and semantic integration in spoken language. J Exp Psychol Learn Mem Cogn 1999;25:394-417.

Vihla M, Lounasmaa OV, Salmelin R. Cortical processing of change detection: dissociation between natural vowels and two-frequency complex tones. Proc Natl Acad Sci USA 2000;97:10590-4.

Walley AC. Spoken word recognition by young children and adults. Cogn Dev 1988;3:137-65.

Winkler I, Lehtokoski A, Alku P, Vainio M, Czigler I, Csepe V, Aaltonen O, Raimo I, Alho K, Lang H, Iivonen A, Naatanen R. Pre-attentive detection of vowel contrasts utilizes both phonetic and auditory memory representations. Brain Res Cogn Brain Res 1999;7:357-69.

Zwitserlood P. Access to phonological-form representations in language comprehension and production. In: Clifton C, Frazier L, Rainer K, editors. Perspectives on sentence processing. Mahwah, NJ: Lawrence Erlbaum; 1994. 